\title{
PENGEMBANGAN KEBUN WISATA PENDIDIKAN (KWP) UNNES MELALUI BIOEDUENTERPREUNERSHIP
}

\author{
Margareta Rahayuningsih, Muh. Abdullah, Vitradesi N, Samsul Arif \\ Jurusan Biologi, Fakultas MIPA, Universitas Negeri Semarang \\ etak_sigid@mail.unnes.ac.id
}

\begin{abstract}
Educational garden of Semarang State University has an area of about two hectares and developed since 2001. Initial management focuses on developing Jelajah Alam Sekitar (JAS) (exploring environment around). The potential of Unnes basically can be used as inventory for the campus environment, and therefore could be used as branding of Conservation University through creative and innovative products with the concept of empowerment. The purpose of this activity is the development and sustainability of the program in Educational Gardens of Unnes through Biodeduenterpreneurship. IbIKK Development of Educational Gardens of Unnes as Conservation University branding through the Bioeduenterpreunership has formed a business unit under the name "Omah Keboen Unnes", draw up a business plan , develop tour packages, education and training, and has been able to improve the infrastructure and services by adding completeness of equipment and facility improvements. With the promotion that is conducted recently, a business unit Omah Keboen Unnes in 2014 has been able to attract consumers with details of 15 people follow the package "Ketan" (Paket Tulang Daung [Package of Bone Leaf]), 100 people follow package JAS to know the biodiversity in KWP, 200 students attend the package outbound and also 60 training plant nursery.
\end{abstract}

Keywords: Educational Garden (KWP), bioeduenterpreunership, universities, conservation

\begin{abstract}
ABSTRAK
Kebun Wisata Pendidikan Unnes (Universitas Negeri Semarang) memiliki luas sekitar dua hektar dan dikembangkan sejak tahun 2001. Awal pengelolaan lebih fokus untuk mengembangkan pendidikan jelajah alam sekitar (JAS). Potensi yang dimiliki Unnes tersebut pada dasarnya dapat dijadikan sebagai inventaris bagi lingkungan kampus dan selanjutnya dapat dijadikan sebagai branding Universitas Konservasi melalui produk kreatif dan inovatif dengan konsep pemberdayaan. Tujuan kegiatan ini adalah pengembangan dan keberlanjutan program di Kebun Wisata Pendidikan Unnes melalui Biodeduenterpreneurship. IbIKK Pengembangan Kebun Wisata Pendidikan Unnes sebagai Branding Universitas Konservasi melalui program Bioeduenterpreunership telah membentuk unit usaha dengan nama "Omah Keboen Unnes", menyusun business plan yang terperinci, mengembangkan paket-paket wisata, pendidikan dan pelatihan, serta telah dapat meningkatkan prasarana dan layanan dengan menambah kelengkapan peralatan dan pembenahan fasilitas. Dengan promosi yang belum lama dilakukan, unit usaha Omah Keboen Unnes pada tahun 2014 telah mampu menarik konsumen dengan rincian 15 orang mengikuti paket Ketan (Paket Tulang Daun), 100 orang mengikuti paket JAS untuk mengenal keanekaragaman hayati di KWP, 200 siswa mengikuti paket outbond dan juga 60 orang mengikuti pelatihan pembibitan tanaman.
\end{abstract}

Kata Kunci : Kebun Wisata Pendidikan (KWP), bioeduenterpreunership, universitas konservasi

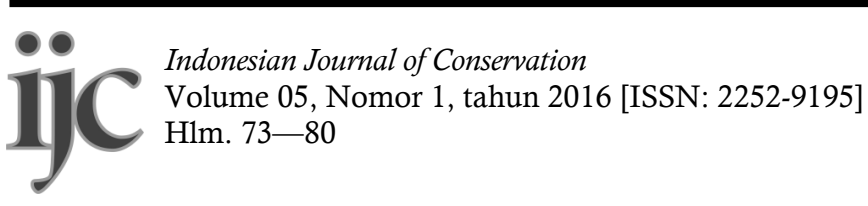




\section{PENDAHULUAN}

Unnes melalui jurusan Biologi FMIPA telah mengembangkan Kebun Wisata Pendidikan (KWP) seluas 2,2 ha. KWP yang dikembangkan Unnes pada awalnya bertujuan menyediakan sarana dan prasarana pendukung pendidikan Biologi, menyediakan alternatif kegiatan pembelajaran sains yang bersifat inovatif, mewujudkan jejaring antara Unnes, dengan institusi pendidikan, pariwisata, swasta dan masyarakat, serta memperkenalkan pendekatan pembelajaran biologi yang memanfaatkan lingkungan sebagai obyek belajar dengan kegiatan yang dikemas dalam suasanna yang menyenangkan dan bersifat mendidik (Bioedutainment)

Di Kebun Wisata Pendidikan terdapat koleksi berbagai jenis tanaman, Kebun Bibit Kampus (KBK), Rumah Penangkaran Kupukupu, dan Rumah Anggrek. Penambahan tumbuhan koleksi tanaman di kebun wisata pendidikan sampai saat ini terus dilakukan, meliputi tumbuh-tumbuhan yang berfungsi dalam mendukung upaya konservasi sumberdaya alam dan lingkungan. Jenis-jenis tumbuhan tersebut antara lain tumbuhan yang berfungsi dalam menjaga siklus hidrologi dan menjaga erosi tanah, tumbuhan lang$\mathrm{ka}$, tanaman obat, tumbuhan yang digunakan oleh burung dan kupu-kupu untuk mendukung kehidupannya serta tumbuhantumbuhan khas yang ada di Indonesia.

Pada tahun 2010-2011 Unnes bekerjasama dengan Dinas Kehutanan Jawa Tengah melalui BP DAS Pemali Jratun seluna membuat dan mengembangkan Kebun Bibit Kampus yang terletak didalam Kebun Wisata Pendidikan tepatnya di bagian sisi utara Kebun Wisata Pendidikan. Keberadaan Kebun Bibit Kampus diperlukan mengingat semakin lama kebutuhan bibit Unnes baik bibit tanaman penghijauan, tanaman buah, tanaman langka, dan tanaman obat semakin meningkat. Bibit yang dikembangkan awalnya hanya jenis tanaman penghijauan dan produksi seperti mahoni, sengon, jabon, gmelina, ketapang, trembesi, serta tanaman buah seperti rambutan, durian, mangga, nangka, dan asem (Rahayuningsih et al 2011). Seiring dengan perkembangan masterplan dan kebutuhan Kebun Wisata Pendidikan sebagai Kebun Wisata yang berbasis edutainment, maka pada awal tahun 2012 mulai memperluas pengembangan bibit tanaman sayur, tanaman hias, dan khususnya tanaman obat. Pengembangan dan optimalisasi Tanaman Obat di Kebun Bibit Kampus secara khusus perlu dilakukan karena berdasarkan hasil inventarisasi jumlah jenis tanaman yang berkhasiat obat di Kebun Bibit Kampus adalah sebanyak \pm 61 jenis dan kebanyakan adalah jenis pohon. Sementara jenis-jenis perdu seperti jahe, kunir, kencur masih terbilang sedikit, padahal jenis-jenis tersebut adalah jenis-jenis yang sudah dan sering dimanfaatkan sebagai bahan baku minuman (jamu) baik dalam bentuk bubuk maupun cair, es krim, dan sebagai bumbu (Rahayuningsih et al. 2012). Sampai pada akhir tahun 2012, berhasil dilakukan penambahan jenis dan jumlah bibit tanaman obat seperti jahe merah, jahe putih, kunir, temulawak, kencur, laos, kunci, lempuyang, temu putih, daun jinten, sere, kayu manis, parijata, jeruk, dan cabai.

Program yang dikembangkan oleh Jurusan Biologi FMIPA Universitas Negeri Semarang bekerjasama dengan Badan Pengembang Konservasi Unnes disebut Bioeduenterpreneurship dengan kegiatan utama sebagai penyedia jasa ekowisata, pembelajaran dan pelatihan tentang alam secara berkelanjutan sehingga terjadi peningkatan kualitas sumber daya manusia, khususnya dibidang pelestarian keanekaragaman hayati. Jenis usaha ini dibidik karena meningkatnya permintaan terhadap produk ekowisata baik di tingkat internasional dan nasional. Hal ini disebabkan karena meningkatnya promosi yang mendorong orang untuk berperilaku positif terhadap alam dan berkeinginan untuk mengunjungi kawasan-kawasan yang masih alami agar dapat meningkatkan kesadaran, penghargaan dan kepeduliannya terhadap alam.

Ditengah semakin menurunnya jumlah kawasan yang masih alami, Unnes tetap menjaga lingkungannya dengan mengembangkan Kebun Wisata Pendidikan (KWP). KWP seluas \pm 2 ha memiliki koleksi berbagai jenis tanaman seperti tanaman obat, tanaman langka, dan tanaman buah. Selain itu, KWP juga memiliki Kebun Bubit Kampus (KBK), rumah anggrek, penangkaran kupu-kupu, outbound area, dan camping ground. Pengembangan KWPK Unnes, juga 
didukung oleh sumber daya manusia yang sangat mumpuni.

Program Bioeduenterpreneurship di KWP

Unnes sendiri bertujuan untuk meningkatkan wawasan dan mengembangkan kemampuan masyarakat dalam pelestarian lingkungan dan keanekaragaman hayati, yang berpendidikan dan berketrampilan tinggi. Selanjutnya diharapkan dapat menciptakan keseimbangan dan kelestarian lingkungan, meningkatkan kualitas hidup dan menjaga kualitas lingkungan.

\section{METODE PELAKSANAAN}

Program Bioeduenterpreneurship berfokus pada jasa pendidikan dan pelatihan, dimana bahan baku utama adalah keahlian dari staf pengajar dan teknisi laboratorium Jurusan Biologi Unnes. Seluruh staf pengajar dan teknisi adalah dosen dan teknisi tetap, sehingga kontinuitas ketersediaannya terjamin. Bila pelatihan memerlukan keahlian tambahan diluar keahlian utama yang dimiliki staff dan teknisi Jurusan Biologi FMIPA Unnes, maka akan dilakukan outsourcing dengan menetapkan kriteria seleksi.

Saat ini di KWP Unnes terdapat 70 jenis koleksi tanaman yang terdiri dari tanaman produksi, tanaman obat, tanaman lang$\mathrm{ka}$, dan tanaman buah. KWP juga dilengkapi dengan fasilitas area outbound dan camping ground, sehingga sering dimanfaatkan sebagai ruang belajar, sekaligus ruang rekreasi yang dikemas dalam konsep Bioeduwisata. Bioeduwisata di KWP Unnes antara lain pengenalan jenis tanaman, Birdwatching dan Butterflywatching. Tidak hanya itu, dalam perjalanannya KWP mengalami berbagai pengembangan antara lain adanya pembangunan rumah penangkaran kupu-kupu (tahun 2010), kebun bibit kampus (tahun 2011) dan rumah anggrek (tahun 2011).

Bisnis inti yang dikembangkan oleh adalah jasa eduwisata dan pelatihan, sehingga ujung tombaknya adalah pelayanan prima (prime service). Seluruh proses diawali dengan proses marketing untuk mencari calon pelanggan (client). Setelah calon pelanggan diperoleh, dilakukan analisis terhadap kebutuhan calon pelanggan tersebut. Berdasarkan analisis tersebut, dilakukan perumusan topik pelatihan, yang dilanjutkan dengan persiapan materi pelatihan dan fasilitas. Setelah itu, dilakukan pelaksanaan pelatihan sesuai rencana yang telah disusun. Di akhir pelatihan dilakukan evaluasi dan analisis hasil yang dikomunikasikan kembali dengan pelanggan. Siklus proses yang seperti ini dilakukan secara penuh dan berulang untuk seluruh jenis pelatihan yang akan dilakukan. Mekanisme evaluasi dan feedback diharapkan merupakan mata rantai pengendalian terhadap kualitas pelatihan yang akan berdampak pada peningkatan kualitas secara berkelanjutan.

Manajemen Bioedupreneurship yang sudah dalam naungan unit usaha Omah Keboen ini berada di bawah koordinasi direktur program. Struktur dibawah ketua program ada dua divisi, yaitu divisi keuangan dan pemasaran, serta divisi HRD dan pengembangan program. Perencanaan produksi difokuskan pada dua produk utama, yaitu edutainment dan pelatihan.

Sasaran yang dibidik melalui program ini antara lain dunia pendidikan (PAUD, TK, SD, SMP, SMA, dan perguruang tinggi), pertanian dan perkebunan, dan masyarakat umum. Pemasaran dilakukan dengan menyebarkan informasi seluas-luasnya. Beberapa metode pemasaran digunakan antara lain: (1) Positioning statement. Metode ini merupakan metode standar yaitu dengan memaksimaklan staf pemasaran untuk memberikan informasi yang detil kepada calon customer; (2) Pricing strategy. Metode pricing strategy adalah metode yang dilakukan dengan memberikan fasilitas diskon bagi peserta yang dapat mengajak calon peserta lain; (3) Promotion strategy. Metode ini memaksimalkan penggunaan media antara lain leaflet, poster, brosur, artikel publikasi, spanduk, dan media elektronik seperti internet. Khusus untuk internet, promosi dilakukan dengan memanfaatkan media jejaring sosial seperti facebook dan twitter. Promosi juga dilakukan dengan memaksimalkan website sebagai sumber informasi dan materi pelatihan yang diselenggarakan, tentu saja dengan persyaratan tertentu untuk dapat men-download informasi tertentu; (4) Developing relationship. Metode ini dilakukan dengan menjalin kerjasama dengan berbagi lembaga yang memiliki afiliasi Unnes, untuk saling mempromosikan dan saling menguatkan posisi sehingga kemajuan bersama dapat diperoleh. 


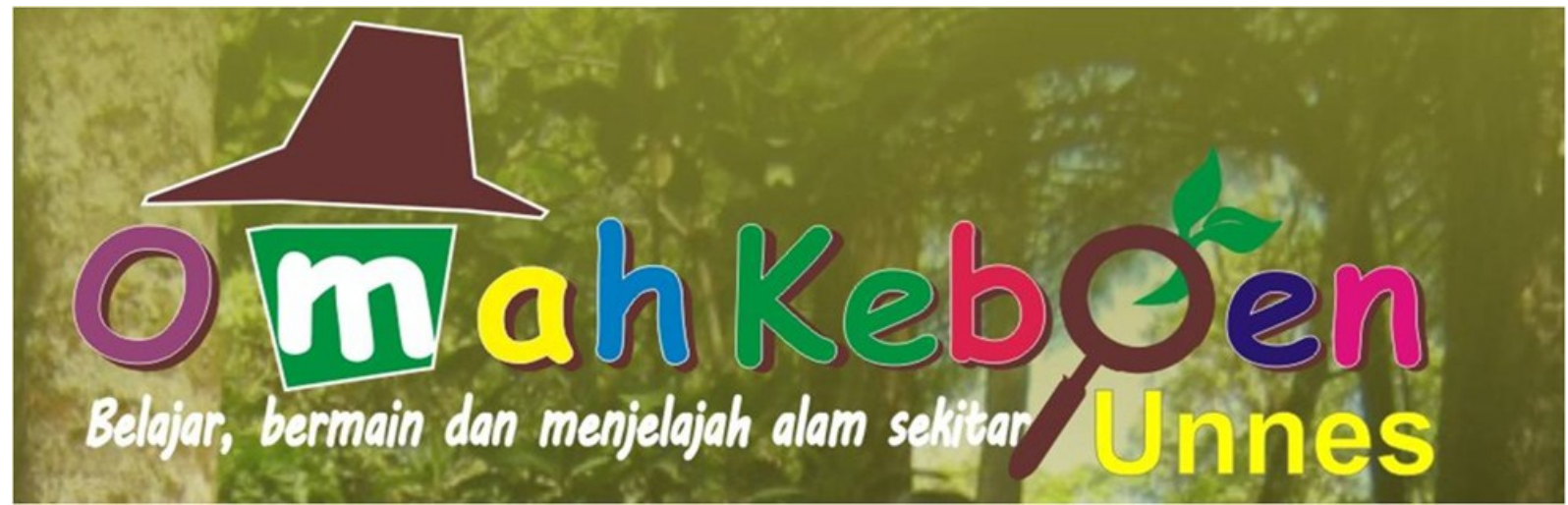

Gambar 1. Logo "Omah Keboen”

Struktur organisasi program terdiri dari seorang ketua program berkualifikasi Doktor, yang dibantu oleh dua staf divisi yang masing -masing berkualifikasi S2, dan S1. Dalam kinerja keseharian untuk urusan kesekretariatan dibantu oleh seorang sekretaris berkualifikasi S1. Untuk pemasaran untuk saat ini dilaksanakan oleh 3 orang bagian marketing berkualifikasi S1. Asisten direktur merupakan 1 garis komando dengan staf divisi keuangan dan pemasaran serta divisi HRD dan pengembangan program, dengan asumsi kinerja maintenance dapat memenuhi kebutuhan kedua sub unit usaha ini. Staf marketing merupakan salah satu pilar dari bergulirnya roda perusahaan, maka antara kedua staf marketing nantinya diharapkan dapat bekerjasama saling mengisi agar metode pemasaran dan penetrasi pasar lebih dalam dan variatif.

Kegiatan Bioeduenterpreneurship dilaksanakan di komplek KWP Unnes yang memiliki luas \pm 2 ha. KWP Unnes terletak di area kampus Unnes sekaran yang lokasinya mudah diakses baik menggunakan kendaraan pribadi maupun kendaraan umum. KWP dilengkapi dengan kebun Bibit kampus, Rumah Penangkaran kupu-kupu, Rumah Anggrek, Area outbond, dan camping ground.

\section{HASIL DAN PEMBAHASAN}

Pengembangan Kebun Wisata Pendidikan Unnes sebagai branding Universitas Konservasi melalui program Bioeduenterpreunership yang dilakukan oleh tim IbIKK Unnes telah mengalami progres yang cukup menggembirakan dibeberapa bidang. Kegiatan awal yang dilakukan adalah dengan membentuk unit usaha dengan nama "Omah Keboen Unnes" (Gambar 1). Setelah unit usaha terbentuk, kemudian menyusun business plan bioeduenterpreneurship yang tersusun dengan rinci.

Unit usaha Omah Keboen telah mengembangkan paket yang sudah ada sebelumya yaitu paket Bioeduwisata menjadi paket baru yang terdiri dari paket Jelajah Alam Sekitar (JAS), Paket Rumah Sains (RUSA), Paket Outbound, Paket Penangkaran Kupukupu (Nangkupu), dan paket kerajinan tulang daun (Ketan) (Gambar 2).

Paket JAS merupakan program outdoor activities yang mengajak peserta membangun konsep secara alamiah, mengeksplorasi Kebun Wisata Pendidikan (KWP) Unnes, mengenal keanekaragaman hayati baik flora maupun fauna, dengan praktik di Kebun Bibit Kampus (KBK), kunjungan ke Rumah Anggrek, dan Rumah Penangkaran Kupukupu. Paket Rusa merupakan paket indoor berupa jelajah laboratorium biologi dan mengajak peserta melakukan berbagai eksperimen yang berhubungan dengan biologi seperti kultur jaringan, genetika, fisiologi hewan dan sebagainya.

Paket Outbound dirancang bagi pelajar, mahasiswa dan umum. Kegiatan ini disajikan dalam bentuk permainanpermainan edukatif yang menarik dan menantang. Peserta akan mendapatkan pengalaman atau ketrampilan yang dapat diimplementasikan dalam kehidupan sehari-hari. Paket nangkupu merupakan paket pelatihan yang memberikan bekal pengetahuan kepada peserta tentang keanekaragaman kupu-kupu dan ketrampilan menangkarkan kupu-kupu sebegai upaya konservasi kupu-kupu secara 

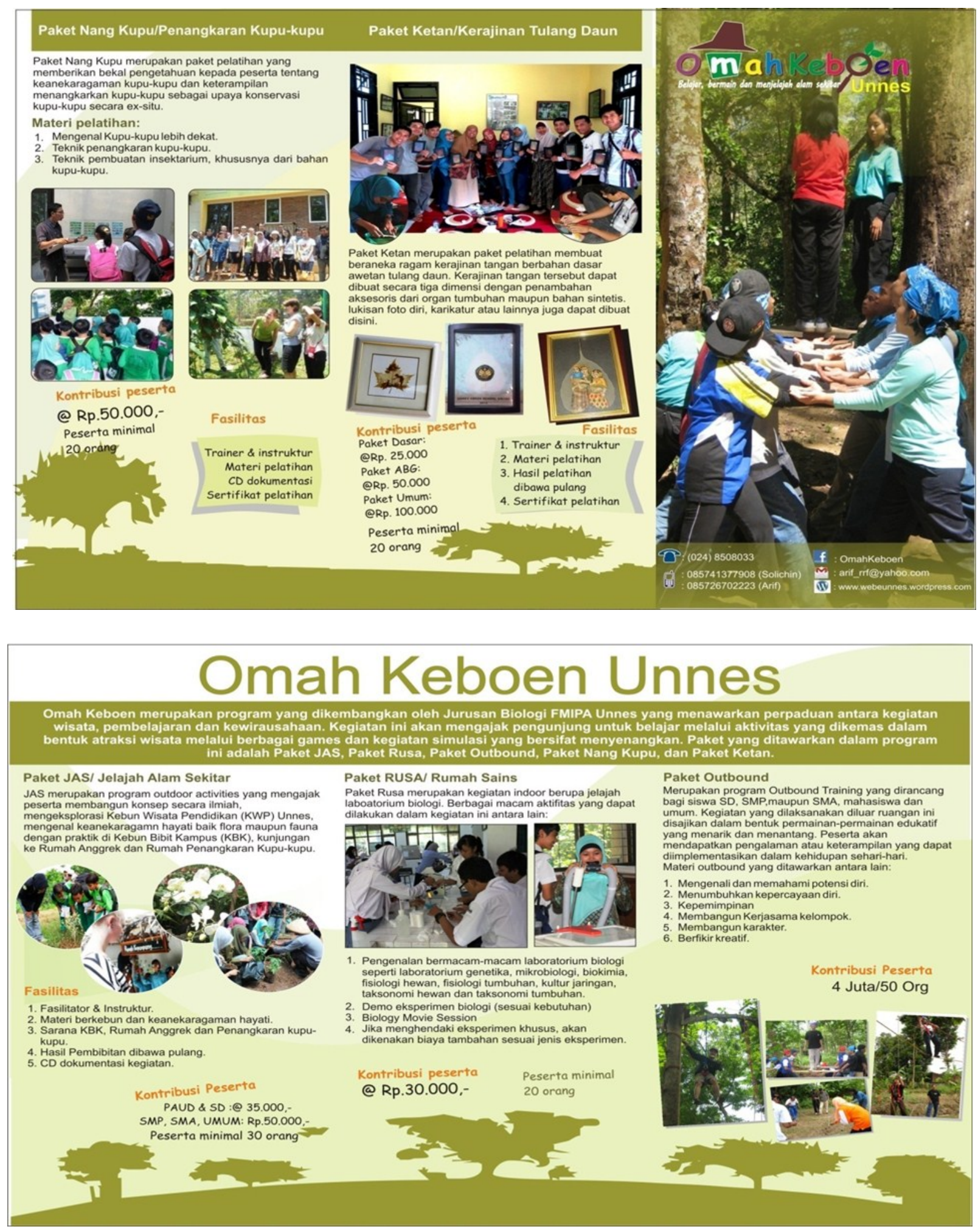

Gambar 2. Paket Program Wisata Pendidikan di Kebun Wisata Pendidikan 
ex-situ. Sedangkan paket Ketan adalah paket pelatihan membuat beranekaragam kerajinan tangan berbahan dasar awetan tulang daun. Kerajinan tangan tersebut dapat dibuat secara tiga dimensi dengan penambahan aksesoris dari organ tumbuhan maupun bahan sintetis.

Agar paket yang sudah di susun dapat berjalan dengan baik, maka kegiatan yang dilakukan adalah dengan peningkatan kapasitas anggota khususnya yang bertugas sebagai fasilitator dalam paket kegiatan. Berkaitan dengan hal tersebut, Omah Keboen telah menyelenggarakan pelatihan tentang performa dan komunikasi dalam profesional kerja dengan menghadirkan pembicara yang ahli dibidangnya.

Kegiatan selanjutnya yang dilakukan adalah penyediaan peralatan yang memadai untuk menunjang kegiatan baik keperluan kesekretariatan maupun untuk paket yang ditawarkan. Kesekretariatan Unit Omah Keboen berada di gedung penangkaran kupukupu dan dilengkapi dengan peralatan standar kantor yang meliputi komputer, printer, LCD projector, ATK, jaringan internet yang dapat digunakan setiap hari dan peralatan kantor lainnya.

Paket JAS didukung dengan adanya Kebun Wisata Pendidikan Unnes yang memiliki koleksi tanaman meliputi tanaman lang$\mathrm{ka}$, tanaman buah dan tanaman obat. Koleksi tanaman dilengkapi dengan papan nama tanaman yang berisi nama ilmiah, nama lokal, dan famili. Di KBK Unnes, telah dibangun bak media tanam sehingga memudahkan peserta dalam belajar pembibitan tanaman. Di area KWP Unnes terdapat Rumah Anggrek dan Rumah Penangkaran kupu -kupu, yang memungkinkan peserta untuk dapat belajar dan mengenal beraneka macam anggrek serta proses metamorfosis kupukupu.

Laboratorium Biologi terdiri dari berbagai macam laboratorium seperti laboratorium fisiologi tumbuhan, genetika, mikrobiologi, fisiologi hewan, fisiologi tumbuhan, kutur jaringan dan lain sebagainya. Pada masing-masing laboratorium dilengkapi dengan peralatan yang mampu menunjang kegiatan praktikum dan pembelajaran sesuai dengan bidang laboratorium masing-masing.

Unit usaha Omah Keboen telah mempersiapkan ruang baru yang terletak pada di laboratorium Biologi lantai 3. Ruang tersebut cukup luas dan difungsikan sebagai ruang transit bagi peserta sebelum peserta mengikuti paket yang telah disediakan. Secara lengkap daftar laboratorium biologi yang dapat menunjang paket Rumah Sains ditampilkan pada Tabel 1.

Unit usaha Omah Keboen telah dapat melengkapi rumah penangkaran kupu-kupu dengan adanya kandang kepompong dan kotak larva untuk paket Nangkupu. Pada ruang pamer juga telah dipasang insektarium yang

Tabel 1. Daftar Laboratorium yang akan dimanfaatkan untuk Paket Rumah Sains (Rusa)

\begin{tabular}{lll}
\hline No & Nama Laboraorium & Lokasi \\
\hline 1. & lab bio kimia & Gedung D11 Lantai 1 \\
2. & lab mikro biologi & Gedung D11 Lantai 1 \\
3. & lab fisiologi tumbuhan & Gedung D11 Lantai 1 \\
4. & lab genetika \& biomolekular & Gedung D11 Lantai 1 \\
5. & lab biokimia & Gedung D11 Lantai 1 \\
6. & lab anatomi tumbuhan & Gedung D11 Lantai 2 \\
7. & lab fisiologi hewan & Gedung D11 Lantai 2 \\
8. & lab kultur jaringan & Gedung D11 Lantai 2 \\
9. & lab mikro tehnik & Gedung D11 Lantai 2 \\
10. & lab ekologi & Gedung D11 Lantai 2 \\
11. & lab struktur tubuh hewan & Gedung D11 Lantai 3 \\
12. & lab taksonomi hewan & Gedung D11 Lantai 3 \\
13. & lab taksonomi tumbuhan & Gedung D11 Lantai 3 \\
\hline
\end{tabular}


berisi berbagai jenis awetan kupu-kupu dan berbagai jenis serangga lainnya. Paket ketan menggunakan peralatan seperti kompor, oven, sikat, scan dan sebagainya. Produk luaran dari paket ini adalah tulang daun hias berwarna-warni, gantungan kunci tulang daun sebagai asesoris yang digemari, dan juga rangkaian tulang daun dengan figura sebagai cinderamata atau penghias dinding rumah.

Instalasi outbound saat ini telah dirancang dan siap untuk dilakukan pemasangan. Pemasangan instalasi outbound yang direncanakan meliputi highrope game, flying fox game, permainan tradisional, dan berbagai permainan lainnya. Konsep outbound yang dirancang unit usaha Omah Keboen tidak hanya sekedar permainan untuk bersenang-senang saja, melainkan disajikan dalam bentuk permainan-permainan edukatif yang menarik dan menantang serta menanamkan rasa cinta lingkungan sehingga peserta akan mendapatkan pengalaman atau ketrampilan yang dapat diimplementasikan dalam kehidupan sehari-hari.
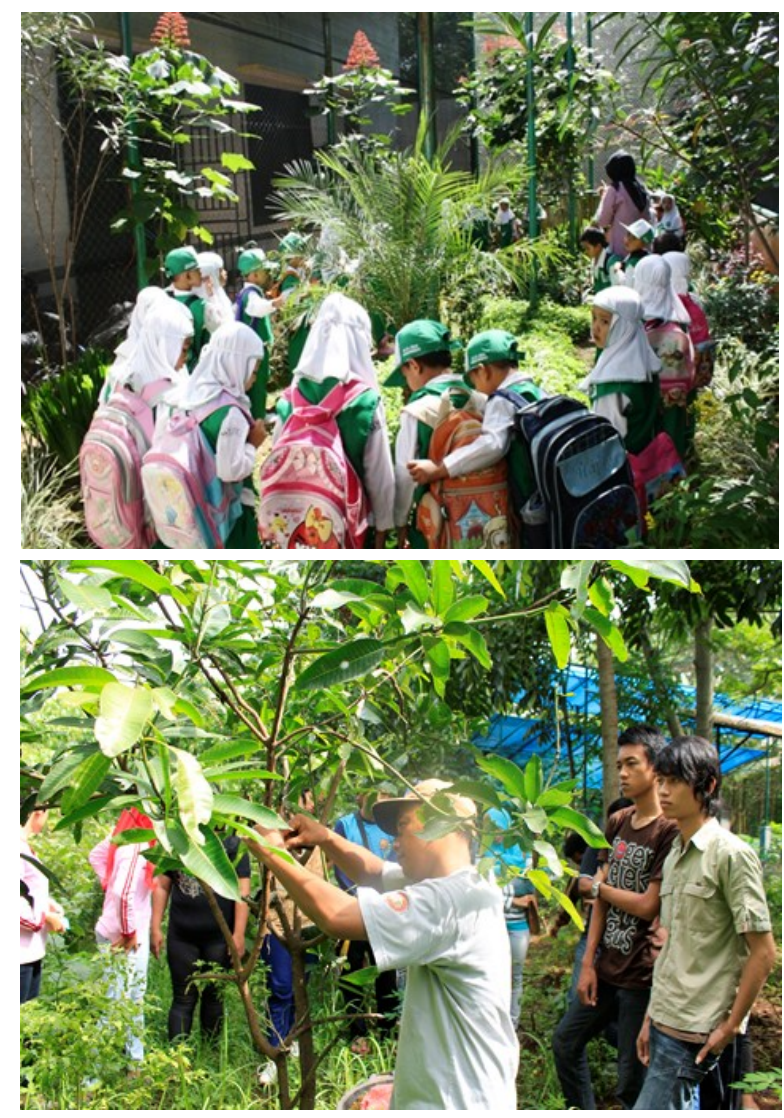

Strategi pemasaran menjadi poin penting yang diperhatikan untuk membidik sasaran pasar yang terdiri dari antara lain dunia pendidikan (PAUD, TK, SD, SMP, SMA, dan perguruang tinggi), pertanian dan perkebunan, dan masyarakat umum. Pemasaran yang telah dilakukan adalah dengan menyebarkan informasi seluas-luasnya melalui media seperti leaflet, katalog, brosur, surat kabar, televisi (An TV)dan media internet. Khusus untuk internet, promosi dilakukan dengan memanfaatkan media jejaring sosial seperti facebook dan dengan memaksimalkan website sebagai sumber informasi (http//:www.webeunnes.wordpress.com). Meskipun promosi belum lama dilakukan, namun unit usaha Omah Keboen sudah mulai mendapatkan customer antara lain 15 orang mengikuti paket Ketan, 100 orang mengikuti paket JAS untuk mengenal keanekaragaman hayati di KWP, 200 siswa paket outbond, dan juga 60 orang mengikuti pelatihan pembibitan tanaman (Gambar 3).

\section{SIMPULAN}

Berdasarkan hasil kegiatan dan pembahasan dapat disimpulkan bahwa IbIKK Pengem-
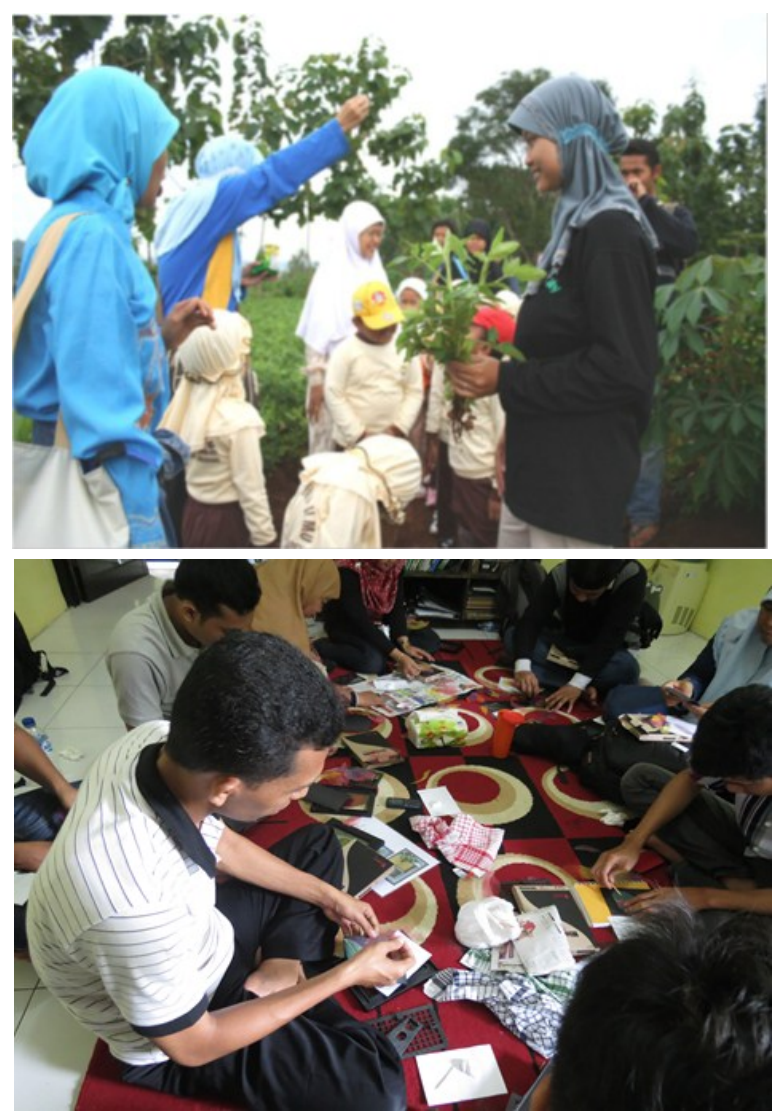

Gambar 3. Peserta paket JAS, pembibitan, dan pelatihan tulang daun. 
bangan Kebun Wisata Pendidikan Unnes Sebagai Branding Universitas Konservasi melalui Program Bioeduenterpreunership telah membentuk unit usaha dengan nama "Omah Keboen Unnes" dan menyusun business plan. Unit usaha Omah Keboen Unnes telah mengembangkan dan menyediakan paket Jelajah Alam Sekitar (JAS), Outbound, Rumah Sains, Penangkaran Kupu-kupu, dan Paket Tulang Daun. Unit usaha Omah Keboen Unnes telah dapat meningkatkan prasarana dan layanan dengan menambah kelengkapan peralatan dan pembenahan fasilitas, sehingga program ini dapat dilaksanakan dengan semestinya. Unit usaha Omah Keboen Unnes merupakan satusatunya unit kegiatan di Unnes dengan kegiatan utama sebagai penyedia jasa ekowisata, pembelajaran dan pelatihan tentang alam, sehingga membuka peluang sebagai embrio usaha baru.

\section{DAFTAR PUSTAKA}

Prajanti, Dian Wisika Sucihatiningsih. 2012. The Policy Effektiveness Of "Go Organic 2010" A Case Study On Implementation and Efficiency Organic Vegetable Culitivation in Semarang Regency. Sosiology Study ISSN 2159-5526 June 2012 Volume 2 Number 6. David Publishing, USA.

Rahayuningsih, dkk. 2010. Menuju Universitas Konservasi-kumpulan dokumen universitas konservasi. Tim Pengembang Universitas Konservasi Unnes.

Rahayuningsih, Rudiatmi, dan Nur Rahayu Utami. 2011. Pengembangan Kebun Bibit Kampus (KBK) di Unnes. DIPA FMIPA.

Rahayuningsih, Rudiatmi, dan Nur Rahayu Utami.2012. Pengembangan Tanaman Obat di Kebun Bibit Kampus (KBK). Badan Pengembang Konservasi.

Rahayuningsih, Margareta. 2013. Redesain Ruang Terbuka Hijau Unnes (Studi kasus Taman Kehati Unnes). Badan Pengembang Konservasi. 